\title{
New Materials in Electrochemical Sensors for Pesticides Monitoring
}

\author{
M. Aránzazu Goicolea, Alberto Gómez-Caballero and Ramón J. Barrio \\ Department of Analytical Chemistry, Faculty of Pharmacy, \\ University of the Basque Country (UPV/EHU) \\ Vitoria-Gasteiz, \\ Spain
}

\section{Introduction}

Pesticides are substances or mixtures thereof, natural or synthetic, formulated to prevent or control any species of plants or pests. The term pesticide includes substances intended for use as plant -growth regulators, defoliants or desiccants.

Once a pesticide is introduced into the environment, either through an application, removal or a spill, it is influenced by processes, such as adsorption, transfer, breakdown and degradation, which determine their persistence, movement and its final fate.

In recent years the growing awareness of the risk associated with intensive use of pesticides has led to a more critical attitude towards the use of agrochemicals. At the same time, many national environmental agencies have been involved in the development of regulations to eliminate or severely restrict the use and production of a number of pesticides.

However in the third millennium, pesticides will continue to play an important role in plant diseases and pest management. Even in developed countries, where farmers are shifting from subsistence agriculture to modern agriculture, pesticide use may increase at a high rate. Therefore, their use should be optimized, bearing in mind the safety to producers and consumers as well as the environmental impact.

Monitoring and exposure data are critical to accurately determine the impact of pesticides on human health and environment. The analytical methods, faster and more cost-effective, can facilitate the collection of data concerning particular target pesticides that may impact on human health and the environment. Advances in miniaturization and microfabrication technology have led to the development of sensitive and selective electrochemical devices for field-based and in situ environmental monitoring (Pellicer et al., 2010). Electrochemical sensors can provide fast, reliable and cost-effective measurement and monitoring methods. Hanrahan et al. (2004) examine the role electrochemical sensors play in environmental monitoring, focusing on recent technological advances in terms of microfabrication, analytical improvements and remote communication capabilities, including also microfluidic integration and submersible devices for remote, continuous monitoring.

The development of in situ electrochemical devices requires proper attention to major issues including reversibility, long-term stability, specificity and changes in natural conditions that may affect the response of interest. 
This review covers publications related to electrochemical sensors that appeared in print between 1999 and 2010. The focus of the chapter is centered on the development and research in electrochemical sensors based on chemical or biological recognition process and the advantages that the nanomaterials provide on the fabrication and electrochemical sensing systems development for pesticides monitoring.

\section{Molecularly imprinted polymer strategy applied to the development of biomimetic sensors}

Chemical sensors and biosensors are very powerful tools in modern analytical sciences. The new demands of environmental analysis, have driven the development of more selective and sensitive sensing systems. An essential component of any detection system is a recognition platform, which is able to bind selectively to a target analyte in the presence of competing analytes. Both synthetic and biologically derived recognition platforms have been successfully incorporated into molecular sensors. Synthetic recognition systems include synthetic molecular receptors (Schrader \& Hamilton, 2005) and functionalized polymers (Senaratne et al., 2005). Biological recognition systems include immobilized antibodies, enzymes, DNA, and aptamers.

Biological recognition platforms generally show higher levels of affinity and selectivity than their synthetic counterparts and may be more easily targeted to specific analytes. In this respect, the molecular imprinting strategy, represents an important field of application for the generation of sensing systems as substitutes for biological antibodies and receptors (Ye \& Mosbach, 2008). Probably, due to the fact that the selectivity against desired target molecules is considerably improved when these type of devices are employed. This technique lies in synthesizing selective recognition sites in a polymeric matrix with a molecular template during the polymer formation. The removal of the template molecule from the polymer matrix reveals binding cavities that are complementary in size and shape to the template molecule and are lined with appropriately positioned recognition groups.

The choice of the functional monomer to generate a proper MIP is very important because it is the component involved in forming chemical bonds with the template (Lanza \& Sellergren, 1999). In order to optimize the selection of the monomer for a target analyte, several studies have suggested that the synthesis takes place by combinatorial approaches (Takeuchi et al., 1999; Yilmaz et al., 1999). Other authors proposed a method which included computational screening of a virtual library of functional monomers against a target molecule, followed by selection of those ones able to form the strongest complex with the template (Haupt, 2001; Subrahmanyam et al., 2001).

Molecularly imprinted polymers (MIPs) are highly cross-linked polymers that share the advantages of both biological and synthetic recognition platforms. MIPs have excellent mechanical, chemical and thermal stability (Svenson \& Nichols, 2001). However, they also possess the ability to be tailored like biological systems with specificity for a molecule of interest such as pesticides (Fuchiwaki et al., 2007; Shoji et al., 2003; Yamazaki et al., 2001).

The inherent specificity of molecularly imprinted materials and their ability to adapt to different formats, have provided many opportunities for integration into sensing applications (Haupt \& Mosbach, 2000; Piletsky et al., 2001).

The development of highly sensitive transducers capable of monitoring the binding process, the development of polymers capable of interacting with the template in terms of required affinity and specificity and the integration of MIP with the transducer, are the critical issues 
in the design of sensors based on MIPs (Blanco-Lopez et al., 2004a; Suryanarayanan et al., 2010).

Electrochemical methods have been widely used for the detection of rebinding almost at the same extent as the optical and mass-based ones, as discussed by Piletsky \& Turner (2002) and Blanco-Lopez et al. (2004b). This is in part due to the easy integration of MIPs in electrochemical sensors.

The MIPs are primarily recognition platforms that do not have any innate signalling properties. Thus, an important challenge in developing MIP-based chemical sensors is the interface between the MIP and the signal transduction device. The coatings of electrodes with molecularly imprinted polymers (MIPs) are an important tool to achieve this goal (Malitesta et al., 1999).

Despite being a well established analytical technique, the use of electrochemical methods incorporating MIPs provides the researcher the challenge of finding a suitable format for the integration of an imprinted film or particles on the electrode. Despite this, the concept of selective uptake of an analyte of interest and the subsequent generation of a proper electrochemical signal opens an attractive pathway for sensor development (Merkoçi \& Alegret, 2002).

There are excellent reviews and monographs of MIPs providing aspects of design, preparation, characterization and application (Alexander et al., 2006; Haupt, 2001; Sellergren, 2001). Different strategies have been investigated for the immobilization of MIPs on electrochemical transducers such as in situ synthesis on electrode surface by electropolymerization (Malitesta et al, 1999) or at a non-conducting surface by chemical grafting (Piletsky et al., 2000) .

The chemical grafting is usually prepared using two strategies "grafting-to" and "graftingfrom" (Advincula et al., 2004; Pyun \& Matyajaszewski, 2001). The "grafting to" technique involves tethering performed end-functionalized polymer chains to a suitable substrate. This technique often leads to low grafting density and low film thickness, as the polymer molecules must diffuse through the existing polymer film to reach the reactive sites on the surface. The steric hindrance for surface attachment increases as the tethered polymer film is thicker. To overcome this problem, the "grafting from" approach can be used and has generally become the most attractive way to prepare thick, covalently tethered polymer brushes with a high grafting density (Zhao \& Brittain, 2000). The "grafting from" technique involves the immobilizing of initiators onto the substrate followed by in situ surface initiated polymerization to generate the tethered polymer brush.

The combination of imprinted films as the sensing element and an electrode as the transducer has been investigated by several groups (Gutierrez-Fernandez et al., 2001; Marx et al., 2004; Shustak et al., 2003). Some of them include molecular imprinting in sol-gel (Gupta \& Kumar, 2008) or surface molecularly imprinted self-assembled monolayers (Li et al., 2006; Mirsky et al., 1999; Piletsky et al., 1999a) as strategies for the immobilization of MIPs on electrochemical transducers.

The surface tailoring by the use of molecularly imprinted polymers (MIPs) over a sol-gel matrix is an important strategy for the production of interfaces in which specific binding is improved by reducing non-specific binding ( Patel et al., 2009a; Patel et al., 2009b).

This technology allows low temperature fabrication of a surface material starting either from a chemical solution or colloidal particles to produce an integrated network. Such network facilitates surface grafting of MIP, and the resulting hybrid possesses high glass-transition temperature with improved molecular specificity and selectivity. 
Other systems, such as self-assembled monolayers (SAMs) and polymer brushes have recently attracted considerable attention due to their noble physicochemical surface property and ease of processing (Boyes et al., 2004). The modification of molecular recognition by SAMs, is based on the formation of rigid nanostructures organized around the template molecule by SAMs at the electrode surface and can be considered as a form of two-dimensional imprinting. The preparation of these systems involves the simultaneous adsorption of the template and mercaptan molecules at a metalic surface. The recognition is possible if specific interactions are developed to form a stable complex between the template and the alkylthiol chain forming the monolayer (Piletsky et al, 1999a). Polymer brushes refer to an assembly of polymer chains which are tethered by one end to a surface or interface. They have recently attracted considerable attention and there have been numerous studies to examine their structure and novel properties (Zhao \& Brittain, 2000).

One way for MIPs deposition on the surface of different types of electrodes is the use electropolymerization techniques. Advantages of electropolymerization include the ability to coat very small or irregularly shaped electrode surfaces with a polymeric film, the ability to control film thickness based upon the amount of charge passed in the case of conducting films or by self-regulation in the case of non conducting films, and the ability to influence both the polymerization rate and the nature of the film via the applied potential use during electropolymerization. To prepare these molecularly imprinted layers on electrodes, such as polypyrrole (Ramanaviciene et al., 2006), overoxidized polypyrrole (Ozkorucuklu et al., 2008), polyaniline (Manisankar et al., 2008a) polyphenylendiamines (Liu et al., 2009; Malitesta et al, 1999), polyphenol (Panasyuk et al., 1999) or in some cases redox polymers such as metalloporphyrins (Gomez-Caballero et al., 2010; Mazzotta \& Malitesta, 2010) have been used. The growth of these types of MIPs depends on the nature of the synthesized polymers. If the resulting polymer is conducting, the polymeric growth is practically unlimited, on the other hand, if the polymer is nonconducting, the growth would be selflimited obtaining very thin polymeric layers (10-100 nm) (Ulyanova et al., 2006).

Recently, conducting polymers have attracted attention as-sensitive layers in electrochemical sensors. These polymers are characterized by a high electrical conductivity and a good electrochemical reversibility, which justify their use as transducer in the fabrication of efficient electrochemical sensors. Thus, the objective of high specificity together with high sensitivity can be achieved by the combination of the concept of Molecularly Imprinted Polymers with the use of conducting polymers. In this context Pardieu et al. (2009) proposed the design of molecularly imprinted conducting polymers (MICPs) as a transducers for the selective and real time recognition of the herbicide atrazine. Two moieties are necessary for the building of such chemically functionalized, conducting polymer-based sensing layer, a molecular sensing unit- functional monomer -, together with a conjugated linker.

Electropolymerization has been successfully utilized for the preparation of electroactive and electroinactive polymers on a variety of conductive surfaces including, glassy carbon (Liu et al., 2006), graphite (Ozcan \& Sahin, 2007; Weetall \& Rogers, 2004) , gold (Feng et al., 2004; Liao et al., 2004), platinum (Xu \& Chen, 2000) or indium tin oxide (Gao et al., 2007).

An electrochemical sensor based on molecularly imprinted polypyrrole membranes is reported by Xie et al. (2010a) for the determination of herbicide 2,4-dichlorophenoxy acetic acid $(2,4-\mathrm{D})$. The sensor was prepared by electropolymerization of pyrrole on a glassy carbon electrode in the presence of $2,4-\mathrm{D}$ as a template. The sensor can effectively improve the reductive properties of 2,4-D and eliminate interferences by other pesticides and 
electroactive species. The method has been successfully applied to the determination of 2,4$\mathrm{D}$ in environmental water samples, with recovery rates ranging from $92 \%$ to $108 \%$.

Also, combinations of two or more functional monomers have been proposed, which originate in most cases copolymers that have higher recognition skills, in comparison with the polymers generated with single monomers. Electro-copolymerization of aniline with ophenilendiamine was successfully used for the preparation of a metamitron selective voltammetric microsensor (Gomez-Caballero et al., 2007). The authors propose the modification of the surface of a carbon fiber microelectrode to create an MIP selective for the herbicide metamitron, employing the electrosynthesis as a technique for modifying the electrodic surface. The response of the synthesized microsensor was able to distinguish the metamitron from other closely related triazine herbicides as isomethiozin or metribuzin.

Electrosynthesis of MIPs can be carried out in aqueous or in organic media, but aqueous media are usually chosen to electrosynthesize imprinted polymers. The nature of the polymerization mixture generally depends on the solubility of the target analyte or the monomers. Gomez-Caballero et al. (2008) propose the synthesis of an MIP amperometric sensor that owned selectivity towards the pesticide 4,6-dinitro-o-cresol, placing particular emphasis on the fact that the methodology could also be used for all other dinitrophenolic pesticides. Because the template concentration was a key factor when imprinted sites had to be generated, in this work a semiorganic media was chosen to carry out the electrogeneration of the copolymer in order to favor the dissolution of the template molecules.

Although the amount of the imprinted sites increases with the increase of the imprinted membrane thickness, thick imprinted membranes could lead to slow diffusion of analytes to the recognition sites and to inefficient communication between the binding sites and transducers (Riskin et al., 2008). To further increase the amount of effective imprinted sites on the sensor surface, the simplest method is to use a higher electrode surface area (He et al., 2008) through the assembly of gold nanoparticles (AuNPs) at the surface of electrodes (Daniel \& Astruc, 2004; Feng et al., 2008; Yu et al., 2003) due to its large specific surface area, good biocompatibility and high conductivity. Herein Xie et al. (2010b) discuss how the combination of surface molecular imprinting on a large surface area of a AuNP-modified glassy carbon electrode produces a high ratio of imprinted sites and, thus, provides an ultrasensitive electrochemical detection of organophosphate pesticides. The combination of surface molecular self-assembly with electropolymerization of aminothiophenol on a larger area of AuNP-modified electrode was expected to produce a high ratio of imprinted sites and to enhance the total amount of effective imprinted sites. The electrochemical sensor not only can strikingly improve the sensitivity and selectivity of pesticide chlorpyrifos analysis but also obtains good repeatability and, thus, can be potentially exploited for the detection of pesticide residues in the environment.

Choong et al. (2009) demonstrated that a free-standing carbon nanotube array serves as a high porosity $3 \mathrm{D}$ platform for the deposition of molecularly imprinted polypyrrol. The greatest advantage of this organised, 3D structure is that the thickness of the MIPPy film coated around each $\mathrm{CNT}$ can be adjusted accordingly to accommodate target molecules with different sizes.

\subsection{Transducers}

Apart from the recognition element, the other important part of the sensor is the transducer. In this chapter we will consider those transducers based on the measurement of a signal 
caused by a change in properties of the system as a result of binding of the analyte with the MIP-transduction by capacitance, conductimetry and potentiometry- or measurement signal if the analyte undergoes electron transfer reaction - amperometry and voltammetry-.

MIPs based conductimetric (Sergeyeva et al., 1999a), voltammetric (Alizadeh, 2009) potentiometric (Prathish et al., 2007) and capacitive sensors (Gong et al., 2004) have been reported for determination of pesticides.

Despite the relatively simple transduction of the potentiometric signal, only a few sensing devices of this kind have been developed. All of them were based on the use of very thin membranes or films (Zhou et al., 2004). Prasad et al. (2007) report a new strategy to construct a potentiometric biomimetic sensor for direct, rapid and highly selective detection of atrazine. The stability, reusability and dynamic response time are analogous to conventional chemical sensors. The utility of the sensor was successfully tested for field monitoring of atrazine in ground waters. D'Agostino et al. (2006) developed a potentiometric sensor for the herbicide atrazine based on a molecularly imprinted polymeric membrane. The membrane was formed directly at the end of a small Teflon tube which was filled with a solution at constant composition, in contact with an internal reference electrode, as in a classical potentiometric cell for ion selective electrode. Atrazine is protoned, and as a consequence, positively charged in aqueous solution at sufficiently low $\mathrm{pH}$. The combination of the positively charged species with the imprinted membrane should produce a variation of the membrane charge. An interesting characteristic of the potentiometric sensor is that a sort time, only a few seconds, is required to reach the equilibrium potential.

Liang et al. (2010) described a novel strategy for the selective and sensitive detection of the neutral specie chlorpyrifos, using polymeric membrane ISE which is based on a uniformsized MIP.

Conductimetry is based on the current flow established by migration of ions of opposite charge, when an electric field is applied between two electrodes immersed in the electrolyte solution. Therefore, the development of an MIP-based conductimetric sensor, then, requires the preparation of the MIP as a membrane. In this sense Sergeyeva et al (1999a) developed an atrazine-sensitive conductimetric sensor using molecularly imprinted polymer membranes. These membranes were prepared by copolymerization of methacrylic acid and tri (ethylene glycol) dimetacrylate, in the presence of atrazine as a template. In order to improve the flexibility and mechanical stability of the membranes, oligourethane acrylate was added to the mixture of monomers. The effect of the membrane composition and the porogen concentration on the magnitude of the conductimetric responses was investigated. Interfacial phenomena can be followed by changes in capacitance or impedance of the system. The requeriment is to have a totally pore-free, thin, dielectric film, usually on gold substrates. Panasyuk et al. (1999) used capacitive detection in conjunction with imprinted electropolymerized polyphenol layers on gold electrodes. In another work, an electropolymerized molecularly imprinted polymer as a selective receptor layer for the pyrethroid insecticide fenvalerate is reported (Gong et al, 2004). A capacitive chemical sensor for fenvalerate based on an electropolymerized molecularly imprinted polymer as sensitive layer was developed. To test the selectivity of the sensor for fenvalerate, an interference test was performed, including common pyrethroid insecticides such as fenpropathrin, deltamethrin, alphamethrin and cypermethrin.

Panasyuk-Delaney et al. (2001) applied the technique of grafting polymerization for the first time to artificial chemoreceptors based on molecularly imprinted polymers. The results 
demonstrated the compatibility of capacitive detection with a chemically sensitive polymer layer obtained by grafting polymerization for the herbicide desmetryn.

Lower detection limits could be obtained by voltammetry and amperometry (Blanco-Lopez et al., 2003; Gutierrez-Fernandez et al, 2001; Lakshmi et al., 2006). These methods, which can be used for electrochemically active substances, are generally slow, being based on selective adsorption from the sample on the polymeric membrane, and quantification of the adsorbed analyte in a different solution.

Voltammetric and amperometric methods can be used to detect the rebinding of nonelectroactive substances too, by methods based on the competition with similar substances able to bind to the active sites on MIP but electrochemically active (Kroger et al., 1999). Amperometric sensors have continued to be the most popular largely due to their simplity, ease of production and the low cost of the devices and instruments.

Other electrochemical transduction methods for obtaining a signal indicating the rebinding of nonelectroactive substances are based on the change of the permeability of MIP membrane as a consequence of the recombination of the nonelectroactive substance (Piletsky et al., 1999b), obtaining conductivity sensors as reported for instance by (Sergeyeva et al., 1999b).

An interesting approach for the amperometric detection of the rebound analyte consists on the use of molecularly imprinted conducting polymers. The permeability change after the rebinding can be investigated also by using an electroactive marker able to diffuse through the membrane and to reach the conducting surface. Pesavento et al. (2009) presents the possibility of an amperometric sensor for non electroactive substances obtained by contacting glassy carbon or graphite electrodes with molecularly imprinted polymeric membranes. The idea was that the mobility of $\mathrm{H}^{+}$ions in acrylic membranes with cation exchange properties is probably high even in relatively thick membranes, and it is expected to be modulated by the rebinding of the template. To illustrate this concept, two template molecules were considered as representative target compounds, cyanuric acid and atrazine. They have an environmental interest, since atrazine is a widely used herbicide, and cyanuric acid is a product of the natural degradation of triazines.

The stage of electron transfer in voltammetry or amperometry leads to products, which may get fouled on the electrode surface, for this reason electrode cleaning solvents (Blanco-Lopez et al, 2003), a simple mechanical polishing (Andrea et al., 2001) or the use of disposable electrodes may be required.(Liang et al., 2005; Pellicer et al, 2010; Sode et al., 2003) .

\section{Micro and nanostructured materials in electrochemical sensors and biosensors}

The most important aspects to consider in the development of electrochemical sensors are the sensitivity, selectivity, long-term stability, response time, portability and low cost. So far, great efforts have been made to meet these needs through research in the development of new materials.

The electrochemical reactions of some pesticides have slow kinetics, causing fouling of the electrodes. This, affects the performance of the electrode during electrochemical measurements. In recent times this problem has been overcome by applying suitable modifiers such as hexadecane (Xu et al., 2002), clay (Manisankar et al., 2005a; Manisankar et al., 2006) stearic acid (Navaratne \& Susantha, 2000) , crown sol gel film (Li et al., 2005a) $\mathrm{ZrO}_{2}$ (Liu \& Lin, 2005) and bismuth film (Du et al., 2008c) on the electrode surface, improving the performance. 
Nafion film modification gave a better selectivity and mass transfer for parathion detection (Zen et al., 1999). Besides, this polymer film selectively preconcentrates the analyte of interest thus improving sensitivity and selectivity.

Metal and semiconductor nanoparticles in the construction of sensing devices have received considerable attention in recent years because of its unique electrocatalytic, chemical and electrical properties (Luo et al., 2006). Silver nanoparticles deposited on the glassy carbon electrode produced better electro catalytic activity and had higher reproducibility than bulky silver. Kumaravel \& Chandrasekaran (2010) propose a new approach by electrochemical co-deposition of silver nanoparticles with a Nafion film on a glassy carbon electrode for the sensing of methyl parathion and parathion. The silver/Nafion co-deposited film offers better properties than silver or Nafion deposited individually. The experimental results showed that the nanosilver/Nafion composite electrode not only exhibited strong electro catalytic activity but also exhibited good reproducibility.

In addition to the modification of the electrode material, research in the field of electrochemical sensors has been developed in the area of miniaturization. Miniature sensors and detectors are becoming widespread devices in analytical laboratories. With this regard the replacement of classical graphite electrode or platinum by microelectrodes is atracting special interest. Microsized electrodes provided currents of lower intensity, greater relationship between the faradaic and capacitive current and reduced ohmic drop and their electrochemical answers change dramatically just by changing the diameter or the length of the electrode. The introduction of micrometer-sized electrodes has led to significant advances in studies of single-molecule detection. Related to this, Lopez de Armentia et al. (1999) proposed successfully the use of a carbon fiber microelectrode for the analysis of the herbicide metamitron.

During the last several years, a few research groups have been exploring different methodologies of manufacturing nanometer-sized disks, bands, cones and arrays of ultramicroelectrodes. Developments in the design and fabrication of ultramicroelectrodes offer considerable promises for advances in electrochemical sensors, being specially useful for environmental monitoring purposes (Draper et al., 1999). Another advantage of ultramicroelectrodes is that oftentimes no supporting electrolyte is necessary, owing to the favorable mass-transfer characteristics of tiny electrodes. Hence, it may be possible to use ultramicroelectrodes to measure analytes having very high redox potentials. In addition to ultramicroelectrodes, chemistry in miniature has also been carried out through chemical analysis on microchips. Microdevices on a micrometer scale have been fabricated using centimeter-sized chips comprised of glass, silicon or inert polymeric materials. As reactions can be completed effectively and quickly, analytical performance on a small scale is improved by means of speed and efficiency (Smirnova et al., 2008).

The advent of nanotechnology has led to great advances in detection strategies. Nanomaterials are attractive because they have conductivity, large surface area, chemical functionality and biocompatibility which make them particularly interesting for the development of electrochemical sensors and biosensors (Hernandez-Santos et al., 2002; Luo et al, 2006; Welch \& Compton, 2006).

The predominant advantages of using electrodes modified with nanomaterials compared to typical macroelectrodes is their large effective surface area, increased mass transport, high catalytic activity, and the ability to exert control over the local environment at the electrode surface (Katz \& Willner, 2004; Welch \& Compton, 2006). 
Carbon nanotubes CNTs have generated great interest in applications based on their field emission and electronic transport properties, their high mechanical strength, high-surface to volume ratio and their chemical properties (Baughman et al., 2002; Rao et al., 2001). The unique properties of CNTs make them extremely attractive for the task of electrochemical sensors (Luo et al., 2001; Luo et al, 2006; Zhao et al., 2002). Recently, it has been shown that CNTs can impart strong electrocatalytic activity, adsorption properties and minimization of surface fouling onto electrochemical devices (Andrews \& Weisenberger, 2004; Salimi et al., 2007; Tu et al., 2005).

CNTs include both single-walled (SWCNTs) and multi-walled (MWCNTs) structures. SWCNTs comprise of a cylindrical graphite sheet of nanoscale diameter capped by hemispherical ends. The closure of the cylinder is result of pentagon inclusion in the hexagonal carbon network of the nanotube walls during the growth process. SWCNTs have diameters typically of $1 \mathrm{~nm}$ with the smallest diameter reported to date of $0.4 \mathrm{~nm}$.

The MWCNTs comprise several to tens of incommensurate concentric cylinders of these graphitic shells with a layer spacing of $0,3-0,4 \mathrm{~nm}$. MWCNTs tend to have diameters in the range 2-100 $\mathrm{nm}$. These can be considered as a mesoscale graphite system, whereas the SWCNTs is truly a single large molecule.

The electronic, chemical and mechanical properties of CNTs can be tailored by replacing some of the carbon atoms with either boron or nitrogen. From the chemical point of view these doped structures would be more likely to react with donor or aceptor molecules, depending on the doping. Although not so far reported in electrochemical sensing systems, these B or N doped CNTs should merit future attention (Hsu et al., 2000; Kuo et al., 2008).

Functionalization of carbon nanotubes with various kinds of materials is gaining more attention as the different properties of the attached functionalities are required for specific applications (De la Torre et al., 2003; Rubianes \& Rivas, 2003). Carbon composites have received considerable attention, thus, Wang \& Musameh (2003) reported on a new and simple avenue for preparing effective CNT/Teflon composite- based electrochemical sensor and biosensors. The use of Teflon as binder for graphite particles has shown to be extremely useful for various electrochemical sensing applications. The resulting CNT/Teflon material brings new capabilities for electrochemical devices by combining the advantages of CNT and "bulk" composite electrodes. The accelerated electron transfer is coupled with minimization of surface fouling and surface renewability.

The use of multiwalled carbon nanotubes (MWCNTs) in composite materials is well established (Andrews et al., 2002; Manisankar et al., 2009; Sun et al., 2002a; Sun et al., 2002b). $\mathrm{Li}$ et al. (2005b) have also made a novel amperometric sensor for determination of the pesticide parathion from a multiwall carbon nanotubes/Nafion film-modified glassy-carbon electrode. Results suggest that the current response to the MWCNT/Nafion film electrode to parathion is highly sensitive and stable.

Carbon nanotubes are hydrophobic materials, rendering difficult the adhesion of metal deposits. In order to improve metal deposition onto nanotubes, two main approaches are possible: surface modification and sensitization activation. The former is associated with the oxidation of the nanotube surface, in order to create functional groups and increase metal nucleation (Sun et al., 2002c). The latter involves the generation of small nuclei to further promote metal deposits on carbon nanotubes (Ang et al., 2000; Liu et al., 2002). In this sense, Sun et al. (2003) show that it is possible to obtain very small $\mathrm{Pt}$ particles deposited onto multiwalled carbon nanotubes (MWCNTs) and that these metal particles are in electrical 
contact, through the MWCNT, with the carbon backing, enabling the composite structure to be used as an electrode.

Also the atom transfer radical polymerization (ATRP) is a very powerful technique in functional macromolecular design and new material preparation, which has been applied successfully to the controlled functionalization of carbon nanotubes. Based on ATRP, some homopolymers and copolymers were grown on the surface of CNTs (Baskaran et al., 2004; Qin et al., 2004; Yao et al., 2003). Thus, such in situ surface initiating ATRP provides a remarkable route to tailor the structure and properties of the modified CNTs and a way to construct novel CNT-based hybrid nanomaterials (Kong et al, 2004).

Usage of conducting polymers as modifiers is a very promising field (Manisankar et al., 2002; Manisankar et al., 2004) because MWCNTs exhibit excellent electrocatalytic and adsorption properties (Ajayan, 1999) and conducting polymers exhibit preferential accumulation of analytes on bound surface functionalities (Manisankar et al., 2005b). In this sense it has been proposed a multiwalled carbon nanotubes modified glassy carbon electrode, covered with polyaniline and polypyrrole coating for the electrochemical reduction of the herbicide isoproturon, the insecticide voltage and the acaricide dicofol (Manisankar et al, 2008a) or of the insecticides cypermethrin, deltamethrin and fenvalerate (Manisankar et al., 2008b; Siswana et al., 2010) report that nanostructured nickel (II) phthalocyanine/multiwalled carbon nanotubes composite supported on a basal plane pyrolitic electrode, could serve as a viable platform for the sensitive electrocatalytic detection of the carbamate pesticide asulam. The selection for the nanoparticles of nickel (II) phthalocyanine is motivated by the envisaged enhanced electrocatalytic properties for highsurface area metallophthalocyanine nanoparticles species. By employing conducting polymer modified electrodes, the sensitivity is increased and the detection limit is considerably lowered (Manisankar et al, 2005b).

Among polymers selected to bond with CNTs, water-soluble polymers are very attractive because the functions of both the polymer and CNTs can be tailored to create one object and the so-prepared water-soluble nanocomposites have potential and versatile applications. So, Kong et al. (2005) proposed two kinds of water soluble anionic polyelectrolyte - polyacrylic acid(PPA) and poly(sodium-4-styrenesulfonate) (PPS), that were grafted onto the convex surfaces of multiwalled carbon nanotubes (MWCNTs) by "grafting from" approach. The process was conducted by the surface-initiating atom tranfer radical polymerization (ATRP) from the initiating sites previously anchored to MWCNTs. The grafting polymer amount can be efficiently controled by the feed ratio of monomer to MWCNT-supported macroinitiator (MWCNT-Br).

On the other hand the carbon nanotubes are excellent substrates for supporting metal nanoparticles. In particular the use of gold particles for the creation of electrochemical sensing devices is proved to be very promising. Although gold is a poor catalyst in bulk form, nanometer-sized gold nanoparticles can exhibit excellent catalytic activity due to their relative high surface area-to-volume ratio, and their interface-dominated properties, which significantly differ from their bulk counterparts (Shipway et al., 2000). Yu et al. (2003) focus their study on the electron-transfer characteristics of gold nanoparticles in polyelectrolyte multilayers, and the capacity of such films (with varying gold nanoparticle loadings) to act as electrochemical sensors.

Zhang et al. (2009) developed an electrochemical sensor based on electrodeposition of gold nanoparticles on a multi-walled carbon nanotubes modified glassy carbon electrodes. Their work was based on the synergistic properties that other authors had found for the 
composite nanoparticles-nanotubes (Jiang \& Gao, 2003). The composite structure increases electrocatalytic activities towards the reduction of the pesticide parathion. Due to the high surface area-to-volume ratios and good interface-dominated properties gold nanoparticles have been widely employed as catalysts (Qu et al., 2008; Shipway et al, 2000).

The remarkable specificity of biological recognition processes has led to the development of highly selective biosensing devices. A biosensor is a self-contained integrated device which is capable of providing specific quantitative or semi-quantitative analytical information using a biological recognition element -biochemical receptor- which is in direct spatial contact with a transducer element. Enzymes are still the most appropriate recognition elements because they combine high chemical specificity and inherent biocatalytic signal amplification.

Biosensor technology is well suited for field monitoring pesticides. Many studies are focused on enhancing the electrochemical properties of electrodes through the modification of the working electrode (Artyukhin et al., 2004) and improving the efficiency of enzyme immobilization (Katz \& Willner, 2004; Saini et al., 2003). So, Zhang et al. ( 2008) described a controllable layer-by-layer self-assembly modification technique of multi-walled carbon nanotubes and poly(diallyldimethylammonium chloride) on glassy carbon electrode and introduced a controllable direct immobilization of acetylcholinesterase on the modified electrode.

Many of the electrochemical biosensors that have been developed for the detection of pesticides are based on the interaction with the enzyme acetylcholinesterase (AChE) (Du et al., 2007a; Du et al., 2007b; Kok \& Hasirci, 2004)

In recent years, works are focused primarily on the oriented and site-specific immobilization of the enzyme, which has become crucial for the rational design of biosensors. Effective immobilization of the enzyme to a solid electrode surface still represents a great challenge for the fabrication of biosensors. General methods include direct physical adsorption onto a solid supporting matrix and a subsequent entrapment in different substrate materials (Sotiropoulou \& Chaniotakis, 2005).

Some authors propose the use of organic conducting polymers as the enzyme-hosting matrix for biomolecules, due to its advantages of permitting a facile electronic charge flow through the polymer matrix, easy preparation, high conductivity and good stability (Njagi \& Andreescu, 2007; Vidal et al., 2003). Recently, nanoparticles, specially the gold nanoparticles have been extensively used owing to their extraordinarily catalytic activity, good conductivity and biocompatibility (Willner et al., 2006). Also, gold nanoparticles and polymers can be assembled to act as an immobilization matrix of AChE. This resulting composite matrix exhibits a porous structure with large effective surface areas, good conductivity and high catalytic activity, which greatly facilitates electron-tranfer processes and the action of the immobilized AChE for organophosphorous pesticides (Gong et al., 2009)

$\mathrm{Qu}$ et al. (2010) propose as electrode modifier a layer-by-layer self-assembled acetylcholinesterase/dendrimers polyamidoamine-Au-carbon nanotubes configuration. The dendrimers polyamidoamine provides to electrode favorable configuration for the immobilization of AChE. This biosensor system was used successfully in pesticides sensing. Usually these methods rely on enzyme immobilization directly onto the electrode surface. Although the proximity between the enzyme molecules and the electroactive surface provides a fast response of the biosensor, it can not overcome the biofouling of the electrode 
surface, which would eventually lead to the deactivation of the biosensor or at least to the worsening of the electrochemical response. After a suitable chemical modification, for example with a polymeric membrane that could provide various functional groups, it is possible the selection of a more appropriate enzyme immobilization protocol. By using a membrane of acrylonitrile (AN) copolymer as a support for the enzyme immobilization, the need of constantly cleaning the electrode surface after each immobilization procedure, could be avoided. The main disadvantage of AN copolymer membranes comes from their hydrophobic and non-conducting properties. The referred disadvantage could be overcome by using carbon nanotubes as electron transfer mediators from the enzyme molecules to the electrode surface (Wang, 2005). The combination of the highly conductive and electrocatalytic behaviour of integrated multiwall carbon nanotubes membrane with the controlled site-specific enzyme immobilization results in a stable and sensitive sensor towards paraoxon (Ivanov et al., 2010).

In order to develop a biosensor for the detection of organophosphate pesticides, a novel acetylcholinesterase biosensor based on an enzyme immobilized in a membrane electrode was described (Sun et al. 2010). The electrode was modified with multiwall carbon nanotubes, and acetylcholinesterase was cross-linked with glutaraldehyde and then attached to chitosan membrane. During the detection, the enzyme membrane was fixed on the surface of multiwall carbon nanotubes/glassy carbon electrode with O-ring and thus the amperometric acetylcholinesterase-multiwall carbon nanotubes/glassy carbon electrode sensor was used for detecting organophosphate pesticides. The biosensor exhibited good reproducibility and stability and provided a new method for detecting organophosphate residues.

Du et al. (2008b) propose the immobilizatión of AChE onto a multiwalled carbon nanotube (MWCNTs) modified electrode prepared by controllable adsorption of the MWCNTs onto hexyl mercaptan self-assembled monolayers. After immobilization a stable biosensor was constructed for rapid determination of carbaryl. Likewise, they have reported the functionalization of carbon nanotubes (CNTs) by cyclodextrins. The amperometric biosensor based on the immobilization of AChE on MWCNTs- $\beta$-cyclodextrin composite modified glassy carbon electrode, has a high sensitivity for organophosphate pesticides (Du et al., 2010).

Likewise quantum dots (QDs) as cellular labeling in electrochemical bioassay were reported (Du et al. 2008a). The authors described a simple enzyme biosensor based on immobilized AchE on CdTe-QDs gold nanoparticles (GNPs) composite modified chitosan microsfere interface. This article analyzes the synergic effect between CdTe QDs to facilitate electrontransfer processes and the action of the chitosan as a matrix for the immobilization of AchE. Recently, amperometric biosensors based on the immobilization of organophosphorus hydrolase $(\mathrm{OPH})$ have gained much attention. An OPH-based biosensor for the detection of organophosphorus was developed by using mesoporous carbon (MC) and carbon black (CB) as anodic layer. The MC/CB/glass carbon layer exhibited an enhanced amperometric reponse relative to a carbon nanotube-modified electrode (Lee et al., 2010).

\section{Enantioselective electrochemical sensors}

The chirality is a very important concept in the field of pesticides, whose significance has been recognized in relation to the relative biological activity of the individual enantiomers (Hegeman \& Laane Remi, 2002) and their use as biological tracers has been also investigated (Bidleman \& Falconer, 1999a; Bidleman \& Falconer, 1999b) 
The movement in the biosphere of chiral pesticides and their residues can be traced through determinations of enantiomeric excesses. Transport phenomena, volatilization, leaching, atmospheric deposition and reactions, abiotic hydrolysis or photolysis do not alter the enantiomeric excess. However, the metabolism of pesticides by microorganisms and enzymes in higher animals can alter it. Therefore the determination of enantiomeric excess indicates the biological degradation of these products and can report the origin of pesticides in ecosystems.

The introduction of different types of enantioselective sensors and biosensors increases the reliability of the assays as the enantiomer can be determined without prior separation, directly from the matrix with only dissolution and dilution step being involved. Many systems have been reported for the molecular recognition of both enantiomers in an injection analysis system using two amperometric biosensors (Stefan et al., 2000a) or with a potentiometric enantioselective membrane electrode for the S-enantiomer assay, and with an amperometric biosensor for the R-enantiomer assay (Stefan et al., 2000b)

Enantioselective immunosensors are the only type that may be considered to be enantiospecific because the antibody is not reacting with the other enantiomer.

One of the most critical tasks in molecular recognition of enantiomeric pairs is the selection of the chiral selector or the enzyme that favors only the reaction with the enantiomer that must be selected (Gübitz \& Schmid, 2004).

Certain chiral selectors can form inclusion complexes or host-guest, in which the analytemolecule guest- is spatially included inside of a host-ligand-molecule. Among these chiral ligands cyclodextrins and crown ethers can be considered as the most representative ones (Maier et al., 2001; Shahgaldian \& Pieles, 2006) . The functionalization of cyclodextrins often improves their enantioselectivity when the grafted groups are able to interact with some families of guests (Bellia et al., 2009).

Another relevant fact to be considered regarding the development of enantioselective sensors is the selection of the best matrix for the electroactive material. The most employed matrices are the carbon paste electrode or polymer based structures.

Also MIPs have promising prospects in chiral discrimination (Mahony et al., 2005; Maier \& Lindner, 2007; Yan \& Ramström, 2004). Most authors propose for this purpose, the synthesis of MIPs by non-covalent bonds.

Recently electrosynthesized polymers such as poly(dopamine) (PDA) and poly(ophenylendiamine) (Po-PD) have been prepared to form a novel well-defined structure MIP at an electrode. The designed copolymer film could be used for the recognition of the enantiomer, as a capacitive sensor (Ouyang et al., 2007)

On the other hand some authors have focused their studies on the "gate effect" which is a phenomenon where solute permeability of the molecularly imprinted polymer membrane changes with specific binding with the template (Piletsky et al, 1999b). The "gate effect" is probably caused by a morphological change in the polymer matrix due to specific binding with the template, similar to the "induced fit" of the natural receptors. Sekine et al. (2007), have evaluated chiral discrimination of phenyl-alanine anilide (PAA) in organic solvents by an electrochemical method using a L- or D- PAA imprinted polymer grafted on an indiumtin-oxide electrode. The results indicate that the gate effect of MIP can discriminate between the template and its analogue by stereochemical structure.

Another alternative would be the association of MIPs with macrocyclic host molecules, to improve the selectivity and the sensitivity particularly in complex liquid phases (Dickert \& Hayden, 1999). Molecules such as cyclodextrins have been thoroughly studied as hosts for 
organic compounds of low molecular weight (Shahgaldian \& Pieles, 2006). These hosts have hydroxyl functional groups that can be used to couple covalently in the polymer matrix. On the other hand crown ethers are macrocyclic polyethers consisting of a number of oxygen atoms, which form a plane, bound by chains of two carbons, some of which contain acid groups. The ring creates a cavity capable of forming complexes with alkali and alkaline earth cations as well as protonated primary amines. The primary amine can penetrate into the cavity forming hydrogen bonds with oxygen atoms, however the enantioseparation comes from the interaction between the substituents of the asymmetric centers and the ring by acid groups by hydrogen bonds and/or electrostatic interactions (Kim \& Spivak, 2003).

New MIPs were developed by (Piletsky et al. 2005) for the enantiomers of phenylalanine using functional monomers such as bis-acryloyl $\beta-\mathrm{CD}$ and 2-acryloylamido-2-methyl-1propanesulfonic acid. The roles of the hydrophobic interacting cyclodextrin and the electrostatic interacting sulfonic acid monomers were examined.

The synthesis of optically active polymers has attracted considerable interest for application as chiral sensors (Shuangyan et al., 2004). These studies have been largely focused on optically active polypyrrole, which is electrochemically deposited on electrodes of platinum or glassy carbon (Liang et al, 2005; Schwientek et al., 1999). There are also many studies that propose the use of optically active polyaniline (Kane-Maguire \& Wallace, 2010).This can be generated via two routes, by doping of base emeraldine with $\left(^{+}\right)$o $(-)$camphorsulfonic acid (HCSA) or by the enantioselective electropolymerization of aniline in the presence of these chiral acids (+) or (-) CSA. The observed macroasymmetry of the polyaniline so generated was rationalised in terms of the polyaniline chain adopting a preferred one-sense helical screw maintained by the dopant anions via electrostatic and hidrogen bonding (Li \& Wang, 2003; Reece et al., 2001). The major limitation of conducting polymer processing arises from their insolubility in most common solvents. The formation of coloidal dispersions is an attractive alternative route to solution processing. Conducting polymer colloids can be produced by electrochemical oxidation of monomers in the presence of a steric stabiliser. Colloids produced electrochemically are formed by intercepting the polymer deposition on the electrode surface utilising hydrodinamic control. This is facilitated by the presence of a steric stabiliser in solution that coats the insoluble polymer upon formation, preventing deposition. The electrochemical approach is advantageous in that the polymer properties can be altered by accurate control of the oxidation potential during polymerisation. This technique also allows a wide range of dopants to be incorporated into the polymer to give different properties. For example, proteins can be incorporated into conducting polymers whilst retaining their biological integrity (Barisci et al., 1999).

Aboutanos et al. ( 1999) reported the preparation of chiral polyaniline-camphorsulfonic acid colloids using silica as the dispersant in the absence of a steric stabiliser, whereas Caramyshev et al. ( 2007) proposed the micelar synthesis of chiral conducting polyaniline in presence de dodecylbenzenesulfonic acid using an enzyme as a catalyst for aniline polymerization. Okuno et al. (2002) also proposed a polypyrrole colloid that had been prepared electrochemically and overoxidized at $+1.5 \mathrm{~V}$ to create a complementary cavity for recognition of molecules structurally similar to the dopant.

Likewise Huang et al. (2008) successfully prepared polypyrrol nanowires by electrochemical polymerization on a platinum electrode, in which chiral camphorsulfonic acid molecules acted as both the dopant and pseudo-template. The enantioselective sensoring and uptaking for corresponding chiral phenylalanine were confirmed. 
On the basis of the undertaken studies it is clear the need to give a step forward in the field of chiral sensing and it is very likely that future trends will be focused on the development of new matrices based on the molecular imprinting technique itself or combined to nanomaterials.

\section{Acknowledgement}

This work was financially supported by the Spanish Minister of Science Innovation (Project CTQ2008-00651/BQU).

\section{References}

Aboutanos, V.; Barisci J. N.; Kane-Maguire L. A. P. \& Wallace G. G. (1999). Electrochemical preparation of chiral polyaniline nanocomposites. Synthetic Metals, 106 (2), 89-95.

Advincula, R.; Brittain W.; Caster K. \& Rühe J. (2004). Polymer Brushes: Synthesis, Characterization, Application, Wiley-VCH., 9783527210333, Weinheim.

Ajayan, P. M. (1999). Nanotubes from Carbon. Chemical Reviews, 99 (7), 1787-1799.

Alexander, C.; Andersson H. S.; Andersson L. I.; Ansell R. J.; Kirsch N.; Nicholls I. A.; O’Mahony J. \& Whitcombe M. J. (2006). Molecularly imprinting science and technology: a survey of the literature for the years up to and including 2003. Journal Molecular Recognition, 19 (2), 106-180.

Alizadeh, T. (2009). High selective parathion voltammetric sensor development by using an acrylic based molecularly imprinted polymer-carbon paste electrode. Electroanalysis, 21 (13), 1490-1498.

Andrea, P.; Miroslav S.; Silvia S. \& Stanislav M. (2001). A solid binding matrix/molecularly imprinted polymer-based sensor system for the determination of clenbuterol in bovine liver using differential-pulse voltammetry. Sensors and Actuators, $B 76$ (1-3), 286-294.

Andrews, R.; Jacques D.; Qian D. \& Rantell T. (2002). Multiwall Carbon Nanotubes: Synthesis and Application. Accounts of Chemical Research, 35 (12), 1008-1017.

Andrews, R. \& Weisenberger M. C. (2004). Carbon nanotube polymer composites. Current Opinion in Solid State \& Materials Science, 8 (1), 31-37.

Ang, L. M.; Hor T. S. A.; Xu G. Q.; Tung C. H.; Zhao S. P. \& Wang J. L. S. (2000). Decoration of activated carbon nanotubes with copper and nickel. Carbon, 38 (3), 363-372.

Artyukhin, A.; Bakajin O.; Stroeve P. \& Noy A. (2004). Layer-by-Layer Electrostatic SelfAssembly of Polyelectrolyte Nanoshells on Individual Carbon Nanotube Template. Langmuir, 20 (4), 1442-1448.

Barisci, J. N.; Hodgson A. J.; Liu L.; Wallace G. G. \& Harper G. (1999). Electrochemical production of protein-containing polypyrrole colloids. Reactive $\mathcal{E}$ Functional Polymers, 39 (3), 269-275.

Baskaran, D.; Mays J. W. \& Bratcher M. S. (2004). Polymer-grafted multiwalled carbon nanotubes through surface-initiated polymerization. Angewandte Chemie International Edition, 43 (16), 2138-2142.

Baughman, R. H.; Zakhidov A. A.; Heer d. \& A. W. (2002). Carbon nanotubes-the route toward applications. Science, 297 (5582), 787-792. 
Bellia, F.; La Mendola D.; Pedone C.; Rizzarelli E.; Saviano M. \& Vecchio G. (2009). Selectively functionalized cyclodextrins and their metal complexes. Chemical Society Reviews, 38 (9), 2756-2781.

Bidleman, T. F. \& Falconer R. L. (1999a). Using enantiomers to trace pesticide emissions. Environmental Science and Technology, 33 (9), 206A-209A.

Bidleman, T. F. \& Falconer R. L. (1999b). Enantiomer ratios for apportioning two sources of chiral compounds. Environmental Science and Technology, 33 (13), 2299-2301.

Blanco-Lopez, M. C.; Lobo-Castañon M. J.; Miranda-Ordieres A. J. \& Tuñón-Blanco P. (2003). Voltammetric sensor for vanillylmandelic acid based on molecularly imprinted polymer-modified electrodes. Biosensors and Bioelectronics, 18 (4), 353-362.

Blanco-Lopez, M. C.; Gutierrez-Fernandez S.; Lobo-Castañon M. J.; Miranda-Ordieres A. J. \& Tuñon-Blanco P. (2004a). Electrochemical sensing with electrodes modified with molecularly imprinted polymer films. Analytical and Bioanalytical Chemistry, 378 (8), 1922-1928.

Blanco-Lopez, M. C.; Lobo-Castañon M. J.; Miranda-Ordieres A. J. \& Tuñon-Blanco P. (2004b). Electrochemical sensors based on molecularly imprinted polymers. TrAC.Trends in Analytical Chemistry, 23 (1), 36-48

Boyes, S.; Granville A.; Baum M.; Akgun B.; Mirous B. \& Brittain W. (2004). Polymer brushes - surface immobilized polymers. Surface Science, 570 (1-2), 1-12.

Caramyshev, A. V.; Lobachov V. M.; Selivanov D. V.; Sheval E. V.; Vorobiev A. K.; Katasova O. N.; Polyakov V. Y.; Makarov A. A. \& Sakharov I. Y. (2007). Micellar peroxidasecatalyzed synthesis of chiral polyaniline. Biomacromolecules, 8 (8), 2549-2555.

Choong, C.-L.; Bendall J. S. \& Milne W. I. (2009). Carbon nanotube array: A new MIP platform. Biosensors \& Bioelectronics , 25 (3), 652-656.

D’Agostino, G.; Alberti G.; Biesuz R. \& Pesavento M. (2006). Potentiometric sensor for atrazine based on a molecular imprinted membrane. Biosensors $\mathcal{E}$ Bioelectronics, 22 (1), 145-152.

Daniel, M.-C. \& Astruc D. (2004). Gold Nanoparticles: Assembly, supramolecular chemistry, quantum-size-related properties, and applications toward biology, catalysis, and nanotechnology. Chemical Reviews, 104 (1), 293-346.

De la Torre, G.; Blau W. \& Torres T. (2003). A survey on the functionalization of singlewalled nanotubes. The chemical attachment of phthalocyanine moieties Nanotechnology Applications for Clean Water, 14 (7), 765-771.

Dickert, F. L. \& Hayden O. (1999). Molecular imprinting in chemical sensing. TrAC, Trends in Analytical Chemistr, 18 (3), 192-199.

Draper, W. M.; Ashley K.; Glowacki C. R. \& Michael P. R. (1999). Industrial hygiene chemistry: keeping pace with rapid change in the workplace. Analytical Chemistry, 71 (12), 33R-60R.

Du, D.; Ding J.; Cai J. \& Zhang A. (2007a). Determination of carbaryl pesticide using amperometric acetylcholinesterase sensor formed by electrochemically deposited chitosan. Colloids and Surfaces, B: Biointerfaces 58 (2), 145-150.

Du, D.; Huang X.; Cai J. \& Zhang A. (2007b). Amperometric detection of triazophos pesticide using acetylcholinesterase biosensor based on multiwall carbon nanotubechitosan matrix. Sensors and Actuators, B: Chemical ,B127 (2), 531-535. 
Du, D.; Chen S.; Song D.; Li H. \& Chen X. (2008a). Development of acetylcholinesterase biosensor based on CdTe quantum dots/gold nanoparticles modified chitosan microspheres interface. Biosensors \& Bioelectronics, 24 (3), 475-479.

Du, D.; Wang M.; Cai J.; Tao Y.; Tu H. \& Zhang A. (2008b). Immobilization of acetylcholinesterase based on the controllable adsorption of carbon nanotubes onto an alkanethiol monolayer for carbaryl sensing. The Analyst, 133 (12), 1790-1795.

Du, D.; Ye X.; Zhang J. \& Liu D. (2008c). Cathodic electrochemical analysis of methyl parathion at bismuth-film-modified glassy carbon electrode. Electrochimica Acta, 53 (13), 4478-4484

Du, D.; Wang M.; Cai J. \& Zhang A. (2010). Sensitive acetylcholinesterase biosensor based on assembly of beta.-cyclodextrins onto multiwall carbon nanotubes for detection of organophosphates pesticide. Sensors and Actuators B: Chemical, B146 (1), 337-341.

Feng, L.; Liu Y.; Tan Y. \& Hu J. (2004). Biosensor for the determination of sorbitol based on molecularly imprinted electrosynthesized polymers. Biosensors $\mathcal{E}$ Bioelectronics, 19 (11), 1513-1519.

Feng, Y.; Yang T.; Zhang W.; Jiang C. \& Jiao K. (2008). Enhanced sensitivity for deoxyribonucleic acid electrochemical impedance sensor: Gold nanoparticle/polyaniline nanotube membranes. Analytica Chimica Acta, 616 (2), 144-151.

Fuchiwaki, Y.; Shimizu A. \& Kubo I. (2007). 6-Chloro-N,N-dietyl-1,3,5-triazine-2,4diamine(CAT) sensor based on biomimetic recognition utilizing a molecularly imprinted artificial receptor. Analytical Sciences, 23 (1), 49-53.

Gao, N.; Xu Z.; Wang F. \& Dong S. (2007). Sensitive biomimetic sensor based on molecular imprinting at functionalized indium tin oxide electrodes. Electroanalysis, 19 (16), 1655-1660.

Gomez-Caballero, A.; Unceta N.; Goicolea M. A. \& Barrio R. J. (2007). Voltammetric determination of metamitron with an electrogenerated molecularly imprinted polymer microsensor. Electroanalysis, 19 (2-3), 356-363.

Gomez-Caballero, A.; Unceta N.; Goicolea M. A. \& Barrio R. J. (2008). Evaluation of the selective detection of 4,6 dinitro-o-cresol by a molecularly imprinting polymer based microsensor electrosynthesized in a semiorganic medium. Sensors and Actuators, B 130 (7), 713-722.

Gomez-Caballero, A.; Ugarte A.; Sanchez-Ortega A.; Unceta N.; Goicolea M. A. \& Barrio R. J. (2010). Molecularly imprinted poly[tetra(o-aminophenyl)porphyrin] as a stable and selective coating for the development of voltammetric sensors. Journal of Electroanalytical Chemistry, 638 (2), 246-253.

Gong, J.-L.; F-C G.; Kuang Y.; Zeng G.-M.; Shen G.-L. \& Yu R. Q. (2004). Capacitive chemical sensor for fenvalerate assay based on electropolymerized molecularly imprinted polymer as the sensitive layer. Analytical and Bioanalytical Chemistry, 379 (2), 302307.

Gong, J.; Wang L. \& Zhang L. (2009). Electrochemical biosensing of methyl parathion pesticide based on acetylcholinesterase immobilized onto Au-polypyrrole interlaced network-like nanocomposite. Biosensors \& Bioelectronics, 24 (7), 2285-2288.

Gübitz, G. \& Schmid M. (2004). Chiral. In Chiral separations. Methods and protocols., Humana Press, 1588291502, Totowa, NJ. 
Gupta, R. \& Kumar A. (2008). Molecular imprinting in sol-gel matrix. Biotechnology Advances, $26(6), 533-547$.

Gutierrez-Fernandez, S.; Lobo-Castañon M. J.; Miranda-Ordieres A. J.; Tuñon-Blanco P.; Carriedo G. A.; Garcia-Alonso F. J. \& Fidalgo J. I. (2001). Molecularly imprinted polyphosphazene films as recognition element in a voltammetric rifamycin SV senso. Electroanalysis, 13 (17), 1399-1404.

Hanrahan, G.; Patil D. G. \& Wang J. (2004). Electrochemical sensors for environmental monitoring: design, development and applications. Journal Environmental Monitoring, 6 (8), 657 - 664.

Haupt, K. \& Mosbach K. (2000). Molecularly imprinted polymers and their use in biomimetic sensors. Chemical Reviews, 100 (7), 2495-2504.

Haupt, K. (2001). Molecularly imprinted polymers in analytical chemistry. The Analyst, 126 (6), 747-756.

He, X.; Yuan R.; Chai Y. \& Shi Y. (2008). A sensitive amperometric immunosensor for carcinoembryonic antigen detection with porous nanogold film and nano$\mathrm{Au} /$ chitosan composite as immobilization matrix. Journal of Biochemical and Biophysical Methods, 70 (6), 823-829.

Hegeman, W. J. M. \& Laane Remi W. P. M. (2002). Enantiomeric enrichment of chiral pesticides in the environment. Reviews of Environmental Contamination and Toxicology, 173 85-116.

Hernandez-Santos, D.; Gonzalez-Garcia M. B. \& Costa Garcia A. (2002). Metal-nanoparticles based electroanalysis. Electroanalysis, 14 (18), 1225-1235.

Hsu, W. K.; Firth S.; Redlich P.; Terrones M.; Terrones H.; Zhu Y. Q.; Grobert N.; Schilder A.; Clark R. J. H.; Kroto H. W. \& Walton D. R. M. (2000). Boron-doping effects in carbon nanotubes. Journal of Materials Chemistry, 10 (6), 1425-1429.

Huang, J.; Wei Z. \& Chen J. (2008). Molecular imprinted polypyrrole nanowires for chiral amino acid recognition. Sensors and Actuators, B: Chemical, B134 (2), 573-578.

Ivanov, Y.; Marinov I.; Gabrovska K.; Dimcheva N. \& Godjevargova T. (2010). Amperometric biosensor based on a site-specific immobilization of acetylcholinesterase via affinity bonds on a nanostructured polymer membrane with integrated multiwall carbon nanotubes. Journal of Molecular Catalysis B: Enzymatic, 63 (3-4), 141-148.

Jiang, L. Q. \& Gao L. (2003). Modified carbon nanotubes: an effective way to selective attachmenteof gold nanoparticles. Carbon, 41 (15), 2923-2929.

Kane-Maguire, L. A. P. \& Wallace G. G. (2010). Chiral conducting polymers. Chemical Society Reviews, 39 (7), 2545-2576.

Katz, E. \& Willner I. (2004). Biomolecule-functionalized carbon nanotubes: applications in nanobioelectronics. Chemphyschem, 5 (8), 1084-1104.

Kim, H. \& Spivak D. (2003). An orthogonal approach to multifunctional molecularly imprinted polymers. Organic letters, 5 (19), 3415-3418.

Kok, F. N. \& Hasirci V. (2004). Determination of binary pesticide mixtures by an acetylcholinesterase-choline oxidase biosensor. Biosensors \& Bioelectronics, 19 (7), 661-665.

Kong, H.; Gao C. \& Yan D. (2004). Controlled functionalization of multiwalled carbon nanotubes by in situ atom transfer radical polymerization. Journal of the American Chemical Society, 126 (2), 412-413. 
Kong, H.; Luo P.; Gao C. \& Yan D. (2005). Polyelectrolyte-functionalized multiwalled carbon nanotubes: preparation, characterization and layer-by-layer self-assembly. Polymer, 46 (46), 8

Kroger, S.; Turner A. P.; Mosbach K. \& Haupt K. (1999). Imprinted polymer-based sensor system for herbicides using differential-pulse voltammetry on screen-printed electrodes. Analytical Chemistry, 71 (17), 3698-3702.

Kumaravel, A. \& Chandrasekaran M. (2010). A novel nanosilver/Nafion composite electrode for electrochemical sensing of methyl parathion and parathion. Journal of Electroanalytical Chemistry, 638 (2), 231-235.

Kuo, H.-F.; Hsu C.-T.; Lien D.-H.; Syue S.-H.; Kao Y.-S.; Li C.-C.; Li Y.-F.; Chin W.; Chang S.C.; Wei B.-Y. \& Hsu W.-K. (2008). Strain promoted conductivity of doped carbon nanotubes. Applied Physics Letters, 93 (22), 223111-233113.

Lakshmi, D.; Sharma P. \& Prasad B. (2006). Development of uric acid sensor based on molecularly imprinted polymer-modified hanging mercury drop electrode. Electroanalysis, 18 (9), 918-927.

Lanza, F. \& Sellergren B. (1999). Method for synthesis and screening of large groups of Molecularly Imprinted Polymers. Analytical Chemistry, 71 (11), 2092-2096.

Lee, J. H.; Park J. Y.; Min K.; Cha H. J.; Choi S. S. \& Yoo Y. J. (2010). A novel organophosphorus hydrolase-based biosensor using mesoporous carbons and carbon black for the detection of organophosphate nerve agents. Biosensors $\mathcal{E}$ Bioelectronics, 25 (7), 1566-1570.

Li, C.; Wang C.; Guan B.; Zhang Y. \& Hu S. (2005a). Electrochemical sensor for the determination of parathion based on p-tert-butylcalix[6]arene-1,4-crown-4 sol-gel film and its characterization by electrochemical methods. Sensors and Actuators, B: Chemical B107 (1), 411-417.

Li, C.; Wang C.; Ma Y.; Bao W. \& Hu S. (2005b). A novel amperometric sensor and chromatographic detector for determination of parathion. Analytical and Bionalytical Chemistry, 381 (5), 1049-1055.

Li, C.; Wang C.; Wang C. \& Hu S. (2006). Development of a parathion sensor based on molecularly imprinted nano-TiO2 self-assembled film electrode. Sensors and Actuators B: Chemical, B117 (1), 166-171.

Li, W. \& Wang H.-L. (2003). Oligomer-assisted synthesis of chiral polyaniline nanofibers. Journal American Chemical Society, 126 (8), 2278-2279.

Liang, H.-J.; Ling T.-R.; Rick J. F. \& Chou T.-C. (2005). Molecularly imprinted electrochemical sensor able to enantioselectivly (sic) recognize D and L-tyrosine. Analytica Chimica Acta, 542 (1), 83-89.

Liang, R.-N.; Song D.-A.; Zhang R.-M. \& Qin W. (2010). Potentiometric sensing of neutral species based on a uniform-sized molecularly imprinted polymer as a receptor. Angewandte Chemie, International Edition, 49 (14), 2556-2559.

Liao, H.; Zhang Z.; Li H.; Nie L. \& Yao S. (2004). Preparation of the molecularly imprinted polymers-based capacitive sensor specific for tegafur and its characterization by electrochemical impedance and piezoelectric quartz crystal microbalance. Electrochimica Acta ,49 (24), 4101-4107.

Liu, G. \& Lin Y. (2005). Electrochemical sensor for organophosphate pesticides and nerve agents using zirconia nanoparticles as selective sorbents. Analytical Chemistry, 77 (18), 5894-5901 
Liu, X.; Li C.; Wang C.; Li T. \& Hu S. (2006). The preparation of molecularly imprinted poly(o-phenylenediamine) membranes for the specific O,O-dimethyl-.alpha.hydroxylphenyl phosphonate sensor and its characterization by AC impedance and cyclic voltammetry. Journal of Applied Polymer Science, 101 (4), 2222-2227.

Liu, Y.; Song Q. J. \& Wang L. (2009). Development and characterization of an amperometric sensor for triclosan detection based on electropolymerized molecularly imprinted polymer. Microchemical Journal, 91 (2), 222-226.

Liu, Z.; Lin X.; Lee J. Y.; Zhang W.; Han M. \& Gan L. M. (2002). Preparation and characterization of platinum-based electrocatalysts on multi-walled carbon nanotubes for proton exchange membrane fuel cells. Langmuir, 18 (10), 4054-4060.

Lopez de Armentia, C.; Sampedro C.; Goicolea M. A.; Gomez de Balugera Z.; Rodriguez E. \& Barrio R. J. (1999). Poly(3-methylthiophene)-coated carbon fiber microelectrode for the voltammetric measurement of herbicide metamitron. Electroanalysis, 11 (16), 1222-1226.

Luo, H.; Shi Z.; Li N.; Gu Z. \& Zhuang Q. (2001). Investigation of the electrochemical and electrocatalytic behavior of single-wall carbon nanotube film on a glassy carbon electrode. Analytical Chemistry, 73 (5), 915-920.

Luo, X.; Morrin A.; Killard A. J. \& Smyth M. R. (2006). Application of nanoparticles in electrochemical sensors and biosensors. Electroanalysis, 18 (4), 319-326.

Mahony, J. O.; Nolan K.; Smyth M. R. \& Mizaikoff B. (2005). Molecularly imprinted polymers-potential and challenges in analytical chemistry. Analytica Chimica Acta, 534 (1), 31-39.

Maier, N. M.; Franco P. \& Lindner W. (2001). Separation of enantiomers: needs, challenges, perspectives. Journal of Chromatography, A 906 (1-2), 3-33.

Maier, N. M. \& Lindner W. (2007). Chiral recognition applications of molecularly imprinted polymers: a critical review. Analytical and Bioanalytical Chemistry, 389 (2), 377-397.

Malitesta, C.; Losito I. \& Zambonin P. G. (1999). Molecularly Imprinted Electrosynthesized Polymers: new materials for biomimetic sensors. Analytical Chemistry, 71 (7), 13661370.

Manisankar, P.; Viswanathan S. \& Prabu H. G. (2002). Electroanalysis of endosulfan and ochlorophenol in polypyrrole coated glassy carbon electrode. International Journal of Environmental Analytical Chemistry, 82 (5), 331-340.

Manisankar, P.; Viswanathan S. \& Prabu H. G. (2004). Determination of direct orange 8 in effluent using a polypyrrole modified electrode. International Journal of Environmental Analytical Chemistry, 84 ( 5), 389-397.

Manisankar, P.; Selvanathan G. \& Vedhi C. (2005a). Utilization of sodium montmorillonite clay-modified electrode for the determination of isoproturon and carbendazim in soil and water samples. Applied Clay Science, 29 (3-4), 249-257.

Manisankar, P.; Viswanathan S.; Pusphalatha A. M. \& Rani C. (2005b). Electrochemical studies and square wave stripping voltammetry of five common pesticides on poly 3,4-ethylenedioxythiophene modified wall-jet electrode. Analytica Chimica Acta, 528 (2), 157-163.

Manisankar, P.; Selvanathan G. \& Vedhi C. (2006). Determination of pesticides using heteropolyacid montmorillonite clay-modified electrode with surfactant. Talanta, 68 (3), 686-692. 
Manisankar, P.; Sundari P. L.; Sasikumar R. \& Palaniappan S. P. (2008a). Electroanalysis of some common pesticides using conducting polymer/multiwalled carbon nanotubes modified glassy carbon electrode. Talanta, 76 (5), 1022-1028.

Manisankar, P.; Sundari P. L. A.; Sasikumar R. \& Roy D. J. (2008b). Voltammetric determination of phenoxybenzyl-type insecticides at chemically modified conducting polymer-carbon nanotubes coated electrodes. Electroanalysis, 20 (19), 2076-2083.

Manisankar, P.; Sundari P. A. \& Sasikumar R. (2009). Square-wave stripping voltammetric determination of some organic pollutants using modified electrodes. International Journal of Environmental Analytical Chemistry, 89 (4), 245-260.

Marx, S.; Zaltsman A.; Turyan I. \& Mandler D. (2004). Parathion sensor based on molecularly imprinted sol-gel films. Analytical Chemistry, 76 (1), 120-126.

Mazzotta, E. \& Malitesta C. (2010). Electrochemical detection of the toxic organohalide 2,4DB using a Co-porphyrin based electrosynthesized molecularly imprinted polymer. Sensors and Actuators, B: Chemical, 148 (1), 186-194.

Merkoçi, A. \& Alegret S. (2002). New materials for electrochemical sensing. Molecular imprinted polymers. Trends in Analytical Chemistry, 21 (11), 717-725.

Mirsky, V. M.; Hirsch T.; Piletsky S. \& Wolfbeis O. (1999). A spreader-bar approach to molecular architecture: formation of stable artificial chemoreceptors. Angewandte Chemie, International Edition, 38 (8), 1108-1110.

Navaratne, A. \& Susantha N. (2000). An electroanalytical sensor for the detection of gramoxone (paraquat). Analytical Letters, 33 (8), 1491-1499.

Njagi, J. \& Andreescu S. (2007). Stable enzyme biosensors based on chemically synthesized Au-polypyrrole nanocomposites. Biosensors \& Bioelectronics, 23 (2), 168-175.

Okuno, H.; Kitano T.; Yakabe H.; Kishimoto M.; Deore B. A.; Siigi H. \& Nagaoka T. (2002). Characterization of overoxidized polypyrrole colloids mprinted with L-Lactate and their application to enantioseparation of amino acids. Analytical Chemistry, 74 (16), 4184-4190.

Ouyang, R.; Lei J.; Ju H. \& Xue Y. (2007). A molecularly imprinted copolymer designed for enantioselective recognition of glutamic acid. Advanced Functional Materials, 17 (16), 3223-3230.

Ozcan, L. \& Sahin Y. (2007). Determination of paracetamol based on electropolymerizedmolecularly imprinted polypyrrole modified pencil graphite electrode. Sensors and Actuators B: Chemical, B127 (2), 362-369.

Ozkorucuklu, S.; Sahin Y. \& Alsancak G. (2008). Voltammetric behaviour of sulfamethoxazole on electropolymerized-molecularly imprinted overoxidized polypyrrole. Sensors, 8 (12), 8463-8478.

Panasyuk-Delaney, T.; Mirsky V. M.; Ulbricht M. \& Wolfbeis O. S. (2001). Impedometric herbicide chemosensors based on molecularly imprinted polymers. Analytica Chimica Acta, 435 (1), 157-162.

Panasyuk, T. L.; Mirsky V. M.; Piletsky S. A. \& Wolfbeis O. S. (1999). Electropolymerized molecularly imprinted polymers as receptor layers in capacitive chemical sensors. Analytical Chemistry, 71 (20), 4609-4613.

Pardieu, E.; Cheap H.; Vedrine C.; Lazerges M.; Lattach Y.; Garnier F.; Remita S. \& Pernelle C. (2009). Molecularly imprinted conducting polymer based electrochemical sensor for detection of atrazine. Analytica Chimica Acta, 649 (2), 236-245 
Patel, A.; Sharma P. \& Prasad B. (2009a). Voltammetric sensor for barbituric acid based on a sol-gel derivated molecularly imprinted polymer brush grafted to graphite electrode. International Journal of Pharmaceutics, 371 (1-2), 47-55.

Patel, A.; Sharma P. \& Prasad B. (2009b). Electrochemical sensor for uric acid based on a molecularly imprinted polymer brush grafted to tetraethoxysilane derived sol-gel thin film graphite electrode. Materials Science $\mathcal{E}$ Engineering, C: Materials for Biological Applications, 29 (5), 1545-1553.

Pellicer, C.; Gómez-Caballero A.; Unceta N.; Goicolea M. A. \& Barrio R. J. (2010). Using a portable device based on a screen-printed sensor modified with a molecularly imprinted polymer for the determination of the insecticide fenitrothion in forest samples. Analytical Methods. DOI: 10.1039/c0ay00329h

Pesavento, M.; D’Agostino G.; Biesoz R.; Albert G. \& (2009). Molecularly imprinted polymer based sensors for amperometric determination of non electroactive substance. Electroanalysis, 21 (3-5), 604-611.

Piletsky, S.; Piletskaya E.; Sergeyeva L.; Panasyuk T. \& El’Skaya A. (1999a). Molecularly imprinted self-assembled films with specificity to cholesterol. Sensors and Actuators, B: Chemical, B60 (2-3), 216-220.

Piletsky, S.; Matuschewski H.; Schedler U.; Wilpert A.; Piletska E.; Thiele T. \& Ulbricht M. (2000). Surface functionalization of porous polypropylene membranes with molecularly imprinted polymers by photograft copolymerization in water. Macromolecules, 33 (8), 3092-3098.

Piletsky, S.; Andersson H. \& Nicholls I. A. (2005). On the role of electrostatic interactions in the enantioselective recognition of phenylalanine in molecularly imprinted polymers incorporating beta-cyclodextrin. Polymer Journal, 37 (10), 793-796.

Piletsky, S. A.; Panasyuk T. L.; Piletskaya E. V.; Nicholls I. A. \& Ulbricht M. (1999b). Receptor and transport properties of imprinted polymer membranes -a review. Journal of Membrane Science, 157 (2), 263-278.

Piletsky, S. A.; Subrahmanyam S. \& Turner A. P. F. (2001). Application of molecularly imprinted polymers in sensors for the environment and biotechnology. Sensor Review, 21 (4), 292-296.

Piletsky, S. A. \& Turner A. P. F. (2002). Electrochemical sensors based on molecularly imprinted polymers. Electroanalysis, 14 (5), 317-323.

Prasad, K.; Prathish K. P.; Gladis J. M.; Naidu G. R. \& Prasada Rao T. (2007). Molecularly imprinted polymer(biomimetic) based potentiometric sensor for atrazine. Sensors and Actuators B, 123 (1), 65-70.

Prathish, K. P.; Prasad K.; Rao T. P. \& Suryanarayana M. (2007). Molecularly imprinted polymer-based potentiometric sensor for degradation product of chemical warfare agents. Talanta, 71 (5), 1976-1980.

Pyun, J. \& Matyajaszewski K. (2001). Synthesis of nanocomposite organic/inorganic hybrid materials using controlled/living radical polymerization. Chemistry of Materials, 13 (10), 3436-3448.

Qin, S.; Qin D.; Ford W. T.; Resasco D. E. \& Herrera J. E. (2004). Polymer brushes on singlewalled carbon nanotubes by atom transfer radical polymerization of n-butyl methacrylate. Journal of the American Chemical Society, 126 (1), 170-176. 
Qu, Y.; Min H.; Wei Y.; Xiao F.; Shi G.; Li X. \& Jin L. (2008). Au-TiO2/Chit modified sensor for electrochemical detection of trace organophosphates insecticides. Talanta, 76 (4), 758-762

Qu, Y.; Sun Q.; Xiao F.; Shi G. \& Jin L. (2010). Layer-by-Layer self-assembled acetylcholinesterase/PAMAM-Au on CNTs modified electrode for sensing pesticides. Bioelectrochemistry, 77 (2), 139-144.

Ramanaviciene, A.; Finkelsteinas A. \& Ramanavicius A. (2006). Basic electrochemistry meets nanotechnology: Electrochemical preparation of artificial receptors based on a nanostructured conducting polymer, polypyrrole. Journal of Chemical Education, 83 (8), 1212-1214.

Rao, C. N. R.; Satishkumar B. C.; Govindaraj A. \& Nath M. (2001). Nanotubes. Chemphyschem, 2 (2), 78-105.

Reece, D. A.; Kane-Maguire L. A. P. \& Wallace G. G. (2001). Polyanilines with a twist. Synthetic Metals, 119 (1-3), 101-102.

Riskin, M.; Tel-Vered R.; Bourenko T.; Granot E. \& Willner I. (2008). Imprinting of molecular recognition sites through electropolymerization of functionalized Au nanoparticles: development of an electrochemical TNT sensor based on .pi.-donor-acceptor interactions. Journal of the American Chemical Society, 130 (30), 9726-9733.

Rubianes, M. D. \& Rivas G. A. (2003). Carbon nanotubes paste electrode. Electrochemistry Communications, 5 (8), 689-694.

Saini, R. K.; Chiang I. W.; Peng H.; Smalley R. E.; Billups W. E.; Hauge R. H. \& Margrave J. L. (2003). Covalent sidewall functionalization of single wall carbon nanotubes. Journal of the American Chemical Society, 125 (12), 3617-3621.

Salimi, A.; Noorbakhsh A. \& Ghadermarzi M. (2007). Amperometric detection of nitrite, iodate and periodate at glassy carbon electrode modified with catalase and multiwall carbon nanotubes. Sensors and Actuators B: Chemical, B123 (1), 530-537.

Schrader, T. \& Hamilton A. D. (2005). Functional synthetic receptors, Wiley-VCH, 9783527306558, Weinheim.

Schwientek, M.; Pleus S. \& Hamann C. H. (1999). Enantioselective electrodes: stereoselective electroreduction of 4-methylbenzophenone and acetophenone. Journal of Electroanalytical Chemistry, 461 (1,2), 94-101.

Sekine, S.; Watanabe Y.; Yoshimi Y.; Hattori K. \& Sakai K. (2007). Influence of solvents on chiral discriminative gate effect of molecularly imprinted poly(ethylene glycol dimethacrylate-co-methacrylic acid). Sensors and Actuators B: Chemical, B127 (2), $512-$ 517.

Sellergren, B. (2001). Molecularly imprinted polymers: man-made mimics of antibodies and their applications in analytical chemistry, Elsevier, 0444828370, New York.

Senaratne, W.; Andruzzi L. \& Ober C. (2005). Self-assembled monolayers and polymer brushes in biotechnology: current applications and future perspectives. Biomacromolecules, 6 (5), 2427-2448.

Sergeyeva, T.; Piletsky S.; Brovko A.; Slinchenko E.; Sergeeva L. \& El'skaya A. (1999a). Selective recognition of atrazine by molecularly imprinted polymer membranes. Development of conductometric sensor for herbicides detection. Analytica Chimica Acta ,392 (2-3), 105-111. 
Sergeyeva, T.; Piletsky S.; Panasyuk T. L.; El'skaya A. V.; Brovko A. A.; Slinchenko E. A. \& Sergeeva L. M. (1999b). Conductimetric sensor for atrazine detection based on molecularly imprinted polymer membranes. The Analyst, 124 (3), 331-334.

Shahgaldian, P. \& Pieles U. (2006). Cyclodextrin derivatives as chiral supramolecular receptors for enantioselective sensing. Sensors, 6 (6), 593-615.

Shipway, A. N.; Lahav M. \& Willner I. (2000). Nanostructured gold colloid electrodes. Advanced Materials, 12 (13), 993-998.

Shoji, R.; Takeuchi T. \& Kubo I. (2003). Atrazine sensor based on molecularly imprinted polymer-modified gold electrode. Analytical Chemistry, 75 (18), 4882-4886.

Shuangyan, H. S.; Guoli S. \& Ruqin Y. (2004). Enantioselective recognition of amino acid by differential pulse voltammetry in molecularly imprinted monolayers assembled on Au electrodes. Electroanalysis, 16 (12), 1019-1023.

Shustak, G.; Marx S.; Turyan I. \& Mandler D. (2003). Application of sol-gel technology for electroanalytical sensing. Electroanalysis, 15 (5-6), 398-408.

Siswana, M. P.; Ozoemena K. I.; Geraldo D. A. \& Nyokong T. (2010). Nanostructured nickel (II) phthalocyanine-MWCNTs as viable nanocomposite platform for electrocatalytic detection of asulam pesticide at neutral $\mathrm{pH}$ conditions. Journal of Solid State Electrochemistry, 14 (8), 1351-1358.

Smirnova, A.; Shimura K.; Hibara A.; Proskurnin M. A. \& Kitamori T. (2008). Pesticide analysis by MEKC on a microchip with hydrodynamic injection from organic extract. Journal of Separation Science, 31 (5), 904-908.

Sode, K.; Ohta S.; Yanai Y. \& Yamazaki T. (2003). Construction of a molecular imprinting catalyst using target analogue template and its application for an amperometric fructosylamine sensor. Biosensors \& Bioelectronics, 18 (12), 1485-1490.

Sotiropoulou, S. \& Chaniotakis N. A. (2005). Lowering the detection limit of the acetylcholinesterase biosensor using a nanoporous carbon matrix. Analytica Chimica Acta, 530 (2), 199-204.

Stefan, R.-I.; Van Staden J. \& Aboul-Enein H. Y. (2000a). Simultaneous detection of S and R captopril using sequential injection analysis. Talanta, 51 (5), 969-975.

Stefan, R.; Van Staden J. \& Aboul-Enein H. (2000b). Amperometric biosensors/sequential injection analysis system for simultaneous determination of S- and R-captopril. Biosensors \& Bioelectronics, 15 (1-2),

Subrahmanyam, S.; Piletsky S.; Piletska E. V.; Chen B.; Karim K. \& Turner A. (2001). Biteand-Switch' approach using computationally designed molecularly imprinted polymers for sensing of creatinine1. Biosensors \& Bioelectronics, 16 (9-12), 631-637.

Sun, X.; Li R.; Lebrun G.; Stansfield B.; Dodelet J. P. \& Desilets S. (2002a). Formation of carbon nanotubes on carbon paper and stainless steel screen by ohmically heating catalytic sites. International Journal of Nanoscience, 1 (3 \& 4), 223-234.

Sun, X.; Stansfield B.; Dodelet J. P. \& Desilets S. (2002b). Growth of carbon nanotubes on carbon paper by ohmically heating silane-dispersed catalytic sites. Chemical Physics Letters, 363 (5,6), 415-421.

Sun, X.; Li R.; Villers D.; Dodelet J. P. \& Desilets S. (2003). Composite electrodes made of Pt nanoparticles deposited on carbon nanotubes grown on fuel cell backings. Chemical Physics Letters, 379 (1,2), 99-104.

Sun, X.; Wang X. \& Zhao W. (2010). Multiwall carbon nanotube-based acetylcholinesterase biosensor for detecting organphosphorous pesticides. Sensor Letters, 8 (2), 247-252. 
Sun, Y.-P.; Fu K.; Lin Y. \& Huang W. (2002c). Functionalized carbon nanotubes: properties and applications. Accounts of Chemical Research, 35 (12), 1096-1104.

Suryanarayanan, V.; Wu C.-T. \& Ho K.-C. (2010). Molecularly Imprinted Electrochemical Sensors. Electroanalysis, DOI: 10.1002/elan.200900616.

Svenson, J. \& Nichols I. A. (2001). Thermal and chemical stability of molecularly imprinted polymers. Analytica Chimica Acta, 435 (1), 19-24.

Takeuchi, T.; Fukuma D. \& Matsui J. (1999). Combinatorial Molecular Imprinting: An approach to synthetic polymers receptors. Analytical Chemistry, 71 (2), 285-290.

Tu, Y.; Lin Y.; Yantasee W. \& Ren Z. (2005). Carbon nanotubes based nanoelectrode arrays: fabrication, evaluation, and application in voltammetric analysis. Electroanalysis, 17 (1), 79-84.

Ulyanova, Y.; Blackwell A. \& Minteer S. D. (2006). Poly(methylene green) employed as molecularly imprinted polymer matrix for electrochemical sensing. The Analyst, 131 (2), 257-261.

Vidal, J.-C.; Garcia-Ruiz E. \& Castillo J.-R. (2003). Recent Advances in Electropolymerized Conducting Polymers in Amperometric Biosensors. Microchimica Acta, 143 (2-3), 93 111.

Wang, J. \& Musameh M. (2003). Carbon nanotube/Teflon composite electrochemical sensors and biosensors. Analytical Chemistry, 75 (9), 2075-2079.

Wang, J. (2005). Nanomaterial-based electrochemical biosensors. The Analyst, 130 (4), 421426.

Weetall, H. H. \& Rogers K. ( 2004). Preparation and characterization of molecularly imprinted electropolymerized carbon electrodes. Talanta ,62 (2), 329-335.

Welch, C. M. \& Compton R. G. (2006). The use of nanoparticles in electroanalysis: a review. Analytical and Bioanalytical Chemistry, 384 (3), 601-619.

Willner, I.; Baron R. \& Willner B. (2006). Growing metal nanoparticles by enzymes. Advanced Materials, 18 (9), 1109-1120.

Xie, C.; Gao S.; Guo Q. \& Xu K. (2010a). Electrochemical sensor for 2,4-dichlorophenoxy acetic acid using molecularly imprinted polypyrrole membrane as recognition element. Microchimica Acta, 169 (1-2), 145-152.

Xie, C.; Li H.; Li S.; Wu J. \& Zhang Z. (2010b). Surface molecular self-assembly for organophosphate pesticide imprinting in electropolymerized poly(paminothiophenol) membranes on a gold nanoparticle modified glassy carbon electrode. Analytical Chemistry, 82 (1), 241-249.

Xu, C.; Wu K.; Hu S. \& Cui D. (2002). Electrochemical detection of parathion at a glassycarbon electrode modified with hexadecane. Analytical and Bioanalytical Chemistry, $373(4-5), 284-288$.

Xu, J. J. \& Chen H. Y. (2000). Amperometric Glucose Sensor Based on Coimmobilization of Glucose Oxidase and Poly(p-phenylenediamine) at a Platinum Microdisk Electrode. Analytical Biochemistry, 280 (2), 221-226.

Yamazaki, T.; Yilmaz E.; Mosbach K. \& Sode K. (2001). Towards the use of MIPs containing imidazoles and bivalent metal complexes for the detection and degradation of organophosphotriester pesticides. Analytica Chimica Acta, 435 (1), 209-214.

Yan, M. \& Ramström O. (2004). Molecularly Imprinted Materials: Science and Technology., Taylor \& Francis CRC Press, 0824753534, New York. 
Yao, Z.; Braidy N.; Botton G. A. \& Adronov A. (2003). Polymerization from the surface of single-walled carbon nanotubes - preparation and characterization of nanocomposites. Journal of the American Chemical Society, 125 (51), 16015-16024.

Ye, L. \& Mosbach K. (2008). Molecular imprinting: synthetic materials as substitutes for biological antibodies and receptors. Chemistry of Materials, 20 (3), 859-868.

Yilmaz, E.; Mosbach K. \& Haupt K. (1999). Influence of functional and cross-linking monomers and the amount of template on the performance of molecularly imprinted polymers in binding assays. Analytical Communications, 36 (5), 167-170.

Yu, A.; Liang Z.; Cho J. \& Caruso F. (2003). Nanostructured electrochemical sensor based on dense gold nanoparticle films. Nano Letters. 3 (9), 1203-1207.

Zen, J. M.; Jou J. J. \& Senthil Kumar A. (1999). A sensitive voltammetric method for the determination of parathion insecticide. Analytica Chimica Acta, 396 (1), 39-44.

Zhang, Y.; Kang T.; Lu L. \& Cheng S. (2008). Preparation and characterization of parathion sensor based on molecularly imprinted polymer. Huanjing Kexue, 29 (4), 1072-1076

Zhang, Y.; Kang T.-F.; Wan Y.-W. \& Chen S.-Y. (2009). Gold nanoparticles-carbon nanotubes modified sensor for electrochemical determination of organophosphate pesticides. Microchimica Acta, 165 (3-4), 307-311.

Zhao, B. \& Brittain W. (2000). Polymer brushes: surface-immobilized macromolecules. Progress in Polymer Science, 25 (5), 677-710.

Zhao, Q.; Gan Z. \& Zhuang Q. (2002). Electrochemical sensors based on carbon nanotubes Electroanalysis, 14 (23), 1609-1613.

Zhou, Y.; Yu B.; Shiu E. \& Levon K. (2004). Potentiometric Sensing of Chemical Warfare Agents: Surface Imprinted Polymer Integrated with an Indium Tin Oxide Electrode. Analytical Chemistry, 76 (10), 2689-2693. 


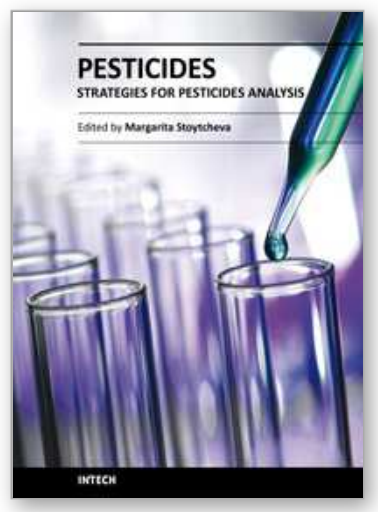

\author{
Pesticides - Strategies for Pesticides Analysis \\ Edited by Prof. Margarita Stoytcheva
}

ISBN 978-953-307-460-3

Hard cover, 404 pages

Publisher InTech

Published online 21, January, 2011

Published in print edition January, 2011

This book provides recent information on various analytical procedures and techniques, representing strategies for reliability, specificity, selectivity and sensitivity improvements in pesticides analysis. The volume covers three main topics: current trends in sample preparation, selective and sensitive chromatographic detection and determination of pesticide residues in food and environmental samples, and the application of biological (immunoassays-and biosensors-based) methods in pesticides analysis as an alternative to the chromatographic methods for "in situ" and "on line" pesticides quantification. Intended as electronic edition, providing immediate "open access" to its content, the book is easy to follow and will be of interest to professionals involved in pesticides analysis.

\title{
How to reference
}

In order to correctly reference this scholarly work, feel free to copy and paste the following:

M. Aranzazu Goicolea, Alberto Gómez-Caballero and Ramón J. Barrio (2011). New Materials in Electochemical Sensors for Pesticides Monitoring, Pesticides - Strategies for Pesticides Analysis, Prof. Margarita Stoytcheva (Ed.), ISBN: 978-953-307-460-3, InTech, Available from: http://www.intechopen.com/books/pesticides-strategies-for-pesticides-analysis/new-materials-inelectochemical-sensors-for-pesticides-monitoring

\section{INTECH}

open science | open minds

\author{
InTech Europe \\ University Campus STeP Ri \\ Slavka Krautzeka 83/A \\ 51000 Rijeka, Croatia \\ Phone: +385 (51) 770447 \\ Fax: +385 (51) 686166 \\ www.intechopen.com
}

\author{
InTech China \\ Unit 405, Office Block, Hotel Equatorial Shanghai \\ No.65, Yan An Road (West), Shanghai, 200040, China \\ 中国上海市延安西路65号上海国际贵都大饭店办公楼 405 单元 \\ Phone: +86-21-62489820 \\ Fax: +86-21-62489821
}


(C) 2011 The Author(s). Licensee IntechOpen. This chapter is distributed under the terms of the Creative Commons Attribution-NonCommercialShareAlike-3.0 License, which permits use, distribution and reproduction for non-commercial purposes, provided the original is properly cited and derivative works building on this content are distributed under the same license. 